\title{
FRACTURES OF THE NECK OF THE FEMUR IN CHILDREN*
}

\author{
A. H. C. Ratliff, Southend-on-Sea, England \\ Formerly Lecturer in Orthopaedic Surgery, Manchester Royal Infirmary
}

"True fractures of the proximal end of the femur [in children] are so rare that no one has a great experience of them" (Blount 1955). The literature is scanty; no detailed study of a large series of cases can be found. The aim of this paper is to discuss the natural history of this injury and to indicate the value of different methods of treatment. I have observed nineteen cases personally. This number was not considered large enough; an approach was therefore made to Fellows and Members of the British Orthopaedic Association, forty-three of whom have permitted me to study the records and radiographs of their cases of femoral neck fractures in childhood.

I must acknowledge my gratitude to these surgeons. At the same time the difficulties of this method of study are emphasised. The material was obtained from many centres, and so many methods of treatment have been employed that it has not been possible to form precise conclusions on the best method of treatment.

The paper is based on a study of seventy-one cases of fracture of the femoral neck in patients under seventeen years old. The median period of observation was between four and five years (a minimum of one year and a maximum of twenty years). Pathological fractures have been excluded from this study; with this exception no selection was employed.

Results of treatment were classified as good, fair or poor, and the method of assessment is summarised in Table I. Particular emphasis was laid on the radiographic appearance, in the belief that this gives a good indication of the likely ultimate prognosis.

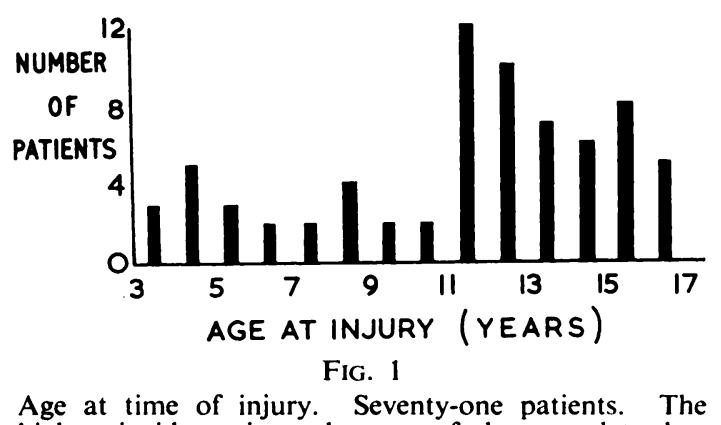
highest incidence is at the ages of eleven and twelve.

\section{INCIDENCE}

In the twelve consecutive years from 1947 to 1959 seven patients under seventeen years old were admitted to the Manchester Royal Infirmary suffering from a fracture of the femoral neck. In the same period about 900 adults were admitted with this injury-approximately 130 adults to every child.

While fractures of the femoral neck in children occur at all ages from three to sixteen years, the highest incidence in the seventy-one patients studied was at the ages of eleven and twelve (Fig. 1).

* Based on a Hunterian Lecture delivered at the Royal College of Surgeons, February 2, 1960. 


\section{CLASSIFICATION}

The fractures may be divided into four groups: transepiphysial, transcervical, basal and pertrochanteric (Table II).

This classification requires explanation. I have found only one detailed report of a transepiphysial fracture in the literature - that of Ingram and Bachynski (1953), who emphasised

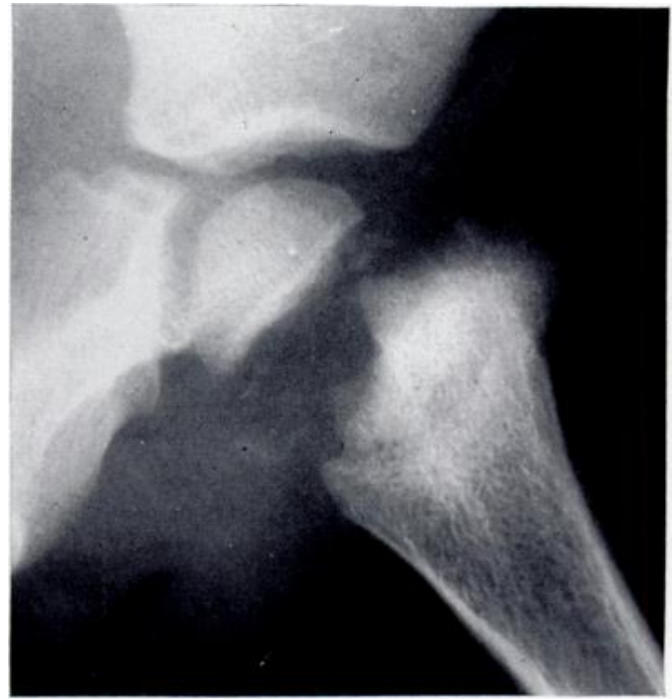

Fig. 2

Radiograph showing a transepiphysial fracture of the femoral neck in a child aged four. The injury was sustained in a motor accident.

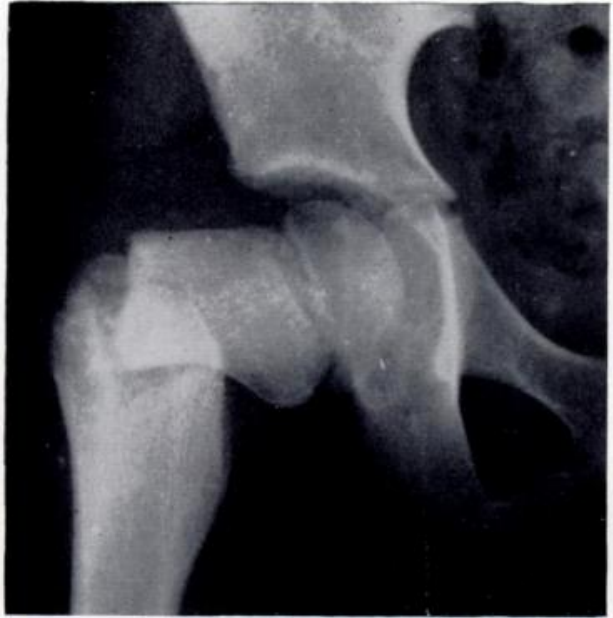

Fig. 3

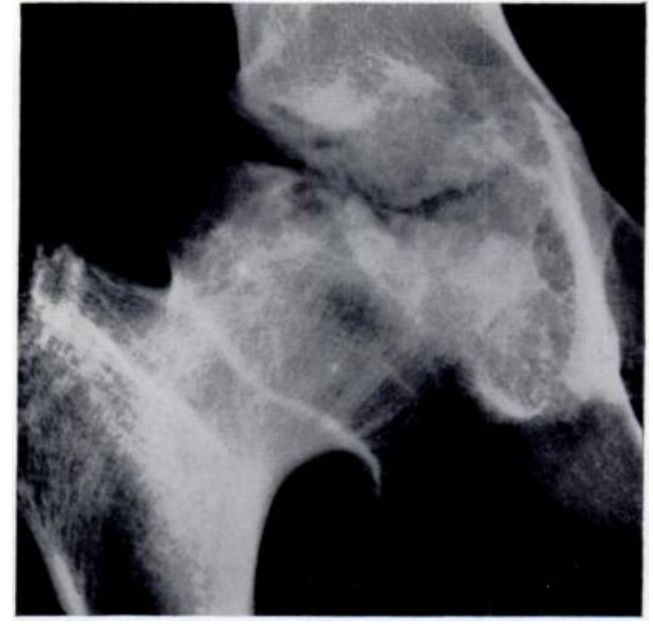

Fig. 4

Avascular necrosis after a basal fracture of the femoral neck. Figure 3-Basal fracture of right femoral neck in a child of nine who was knocked down by a car. Figure 4-Radiograph of same hip five years later, showing severe diffuse avascular necrosis.

that this fracture is " an acute traumatic separation of a previously normal epiphysis." This distinction is not an easy one in the adolescent (McDougall 1961). In this series there were two instances of separation occurring at the epiphysial plate. It was considered that these injuries were fractures and not epiphysiolyses, because both occurred in young children (aged four years) and were produced by major violence in road accidents (Fig. 2).

VOL. 44 B, NO. 3, AUGUST 1962 
TABLE I

The Assessment of Results

\begin{tabular}{|c|c|c|c|}
\hline & Good & Fair & Poor \\
\hline Pain . & None or " ignores" & Occasional & "Disabling" \\
\hline Movement . & Full or terminal restriction & Greater than 50 per cent & Less than 50 per cent \\
\hline Activity & Normal or avoids games & Normal or avoids games & Restricted \\
\hline $\begin{array}{l}\text { Radiographic } \\
\text { indications . }\end{array}$ & $\begin{array}{l}\text { Normal or some } \\
\text { deformity of the } \\
\text { femoral neck }\end{array}$ & $\begin{array}{l}\text { Severe deformity of } \\
\text { the femoral neck. } \\
\text { " Mild" avascular necrosis }\end{array}$ & $\begin{array}{c}\text { Severe avascular necrosis. } \\
\text { Degenerative arthritis. } \\
\text { Arthrodesis }\end{array}$ \\
\hline
\end{tabular}

TABLE II

Site and Nature of Fracture in Seventy Patients (One excluded because precise site of fracture was unknown)

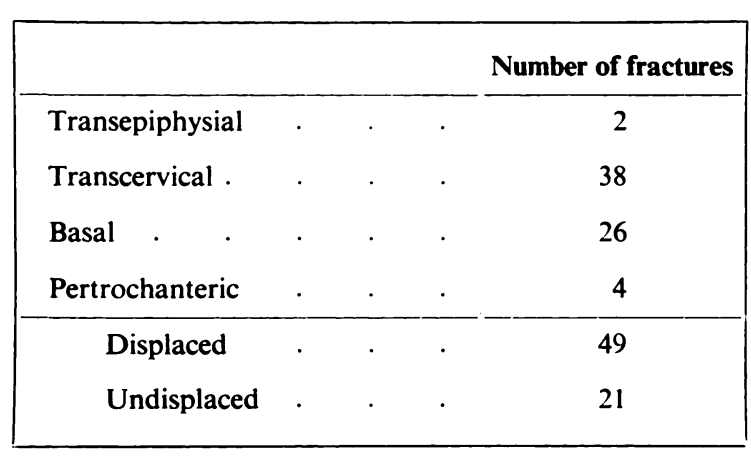

TABLE III

The Mechanism of Injury in Seventy-one Patients

\begin{tabular}{|c|c|c|c|}
\hline Type of injury & $\begin{array}{l}\text { Number of } \\
\text { fractures }\end{array}$ & Mechanism of injury & $\begin{array}{l}\text { Number of } \\
\text { fractures }\end{array}$ \\
\hline \multirow{4}{*}{ Severe . } & \multirow{4}{*}{54} & Fall from a height & 24 \\
\hline & & Knocked down-motor accident & 16 \\
\hline & & Fall off bicycle & 11 \\
\hline & & Fall from a swing & 3 \\
\hline \multirow{2}{*}{ Mild } & \multirow[b]{2}{*}{7} & Slipped while walking & 6 \\
\hline & & Pushed over & 1 \\
\hline Miscellaneous & 9 & & \\
\hline Unknown & 1 & & \\
\hline
\end{tabular}


It will be seen that the commonest fracture was transcervical, and not, as is usuallystated, basal. Examination of the radiographs after reduction, particularly the lateral views, is essential in classifying these fractures. Examples of these types of fracture are shown in Figures 2, 3, 18 and 21.

\section{MECHANISM OF INJURY}

This study confirmed previous reports (Colonna 1928, Carrell and Carrell 1941, Ingram and Bachynski 1953) that a fracture of the neck of the femur in a child usually results from severe violence (Table III).

In nineteen cases the child sustained major injuries other than the fracture of the femoral neck. The most frequent additional lesion was a head injury, which occurred in eleven children.

Four children sustained multiple injuries which endangered life. In sixteen patients there was evidence from the documents of direct violence to the hip.

It may be concluded that a fracture of the femoral neck in a child is usually produced in different circumstances from those causing the common fracture in the elderly woman.

\section{DIAGNOSIS}

Detailed discussion of the diagnosis is unnecessary, but one observation is worthy of mention. There was delay in diagnosis in only two patients in this series, both of whom sustained undisplaced fractures. In all but these cases immediate severe disability necessitated early admission to hospital. I am unable to agree with Whitman (1900) and Colonna (1928) that this injury is associated with a mild disability.

\section{COMPLICATIONS}

This study confirmed an impression from the literature that the incidence of complications after fracture of the femoral neck in childhood is high.

AVASCULAR NECROSIS

Radiographic changes similar to those customarily regarded as evidence of avascular necrosis of the proximal fragment occurred in children of all age groups and developed in thirty patients ( 42 per cent): in twenty-six the fragments had been displaced and in four there

TYPE OF NECROSIS

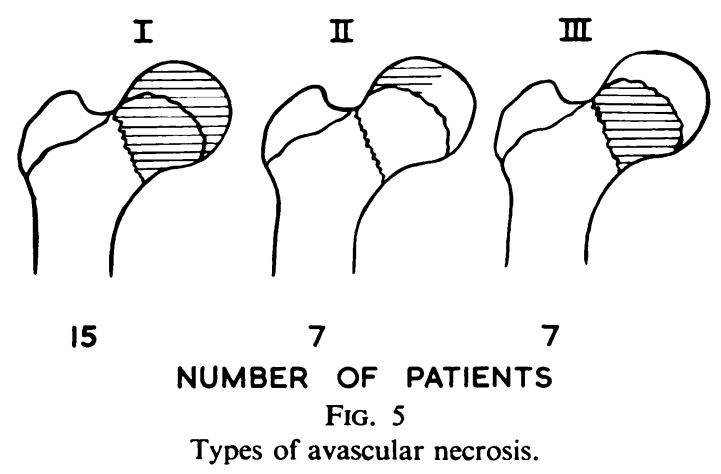

was never any displacenient. Three of these cases of avascular necrosis complicating undisplaced fractures of the neck of the femur in children have previously been published in detail by Durbin (1959).

Twenty-three of the thirty patients whose fractures produced avascular necrosis of part or all of the proximal fragment sustained transcervical fractures. In six cases the fractures occurred at the base of the neck. In one other case the level of the fracture was not clearly 
shown in the documents or in radiographs which I was able to study. Avascular necrosis may develop after a basal fracture in a child (Figs. 3 and 4). So far as I am aware this complication never occurs after a basal fracture in an adult.

Avascular necrosis always appeared within one year after injury. I have been unable to confirm the findings of McDougall (1961), who stated "that the radiological signs of avascular necrosis may not be obvious for two years after an injury." Premature fusion of the upper femoral epiphysial plate was sometimes an early sign of avascular necrosis.

Avascular necrosis was diagnosed in this series upon the characteristic radiographic appearance of increased density. Three patterns of necrosis were noted (Fig. 5). In fifteen patients the increased density was diffuse and was accompanied by a total collapse of the epiphysis (Type I). The radiographic appearances were similar to those observed after a fracture of the femoral neck in an adult. In seven patients the changes were less marked, were localised and were accompanied by minimal collapse of the epiphysis (Type II). In the third

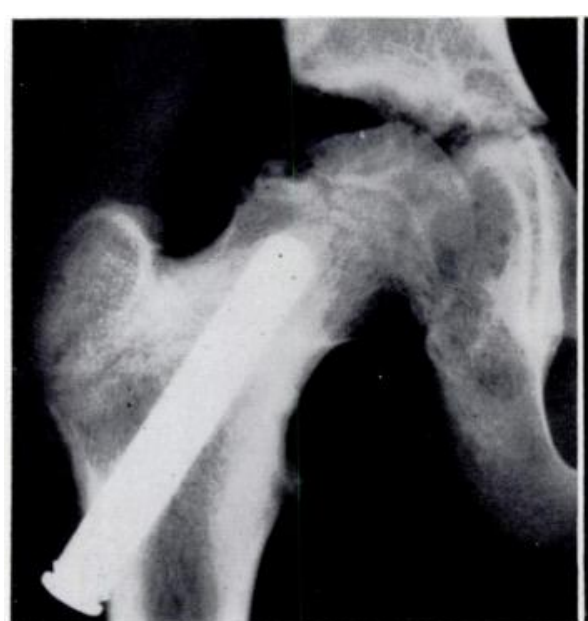

FIG. 6

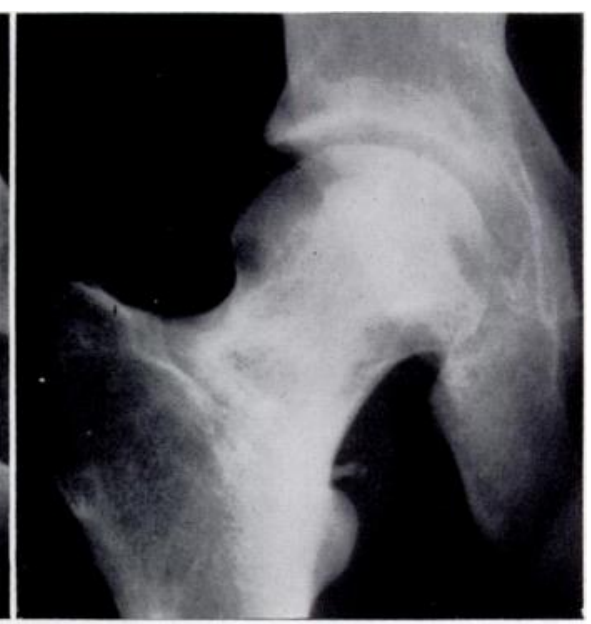

FiG. 7

Avascular necrosis Type II. Figure 6-Radiograph of hip of a child of eleven, eleven months after transcervical fracture which was fixed internally with a trifin nail. Mild avascular necrosis localised to the lateral part of the upper femoral epiphysis. Figure 7-The same hip six years later. Appearances almost normal.

type the necrosis appeared to be confined to the femoral neck and produced the radiographic appearance which was first mentioned by McDougall as recently as $1961 .^{*}$ In seven patients a uniform increase in density appeared in the femoral neck shortly after the fracture occurred, accurately outlined proximally by the epiphysial plate and distally by the fracture line. The capital epiphysis appeared less dense than the femoral neck and did not collapse or fragment. It is noteworthy that with one exception these patients were all eleven years old or younger. In this group there was a striking incidence of premature fusion occurring at the upper femoral epiphysial plate, which occurred in six out of seven patients with this type of necrosis.

The radiographic appearances of avascular necrosis in one patient did not conform with any of the three patterns described above, and this case will be mentioned later. Examples of these types of avascular necrosis are shown in Figures 4, 6, 7, 8, 9 and 10.

Those patients with severe avascular necrosis (Type I) obtained a fair or poor result. In contrast, the result was good in three patients after avascular necrosis of the femoral neck (Type III), and in two patients where changes were localised to part of the upper femoral epiphysis (Type II). The presence of avascular necrosis usually affected the prognosis adversely

* At the time the lecture on which this paper is based was delivered, the occurrence of avascular necrosis in the neck of the femur had not been recorded, as far as the author is aware. 
but there were some notable exceptions (Figs. 6 and 7). No evidence was found that this complication was more likely to occur with any one form of treatment.

The cause of these three types of avascular necrosis is not known. However, a possible explanation can be offered, based on recent experimental studies of the blood supply of the head and neck of the femur in the child. Trueta (1957) has shown that this differs in two respects from the state of affairs in the adult. First, there is no significant anastomosis between the blood vessels supplying the epiphysis and those supplying the metaphysis; the epiphysial

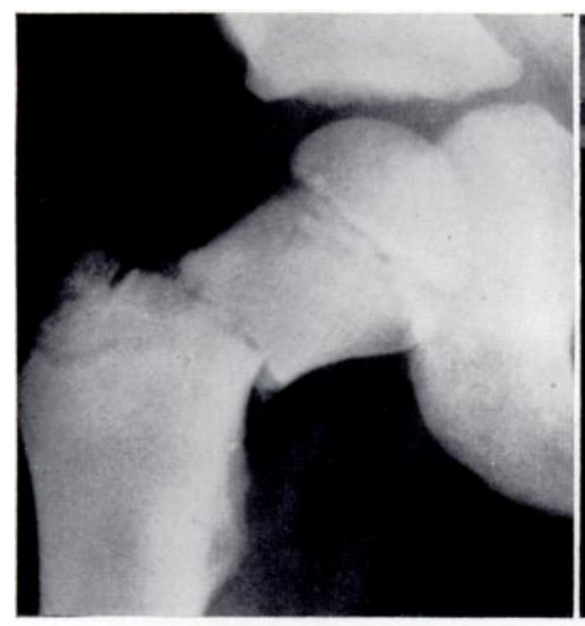

FIG. 8

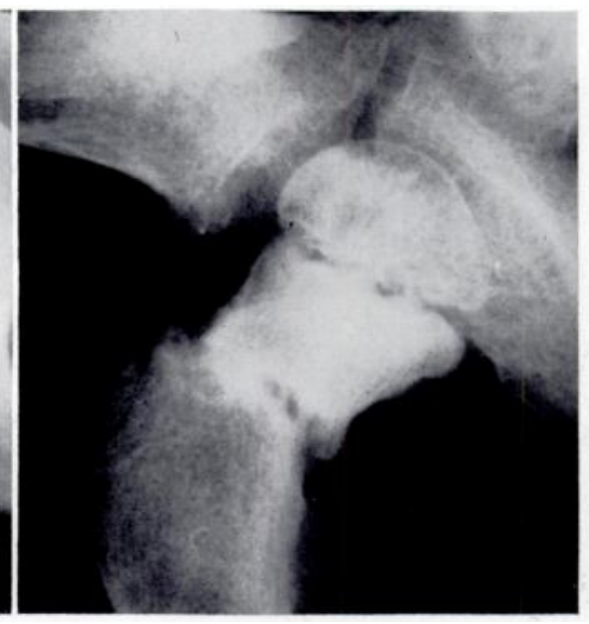

FiG. 9

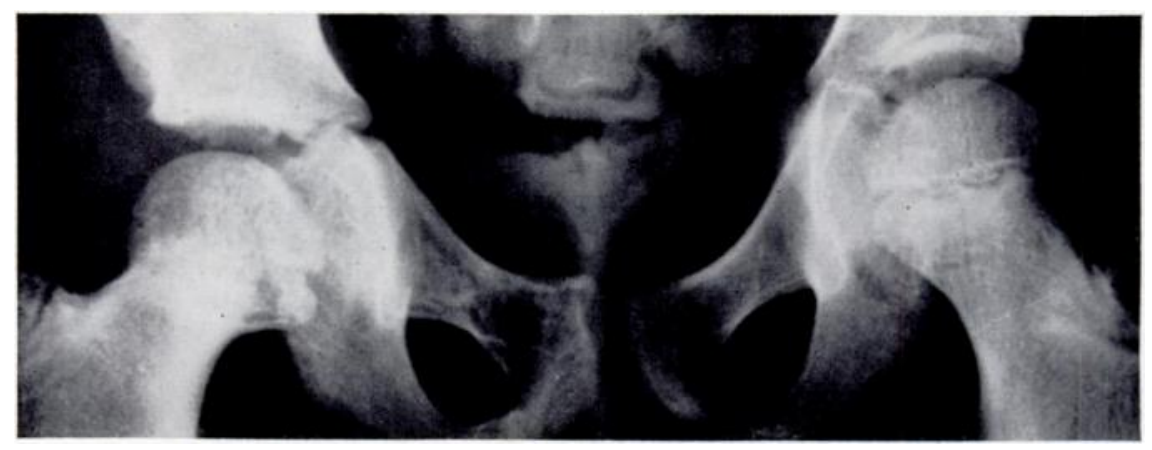

Fig. 10

Avascular necrosis of femoral neck (Type III) and premature epiphysial fusion. Figure 8Radiograph showing fracture of femoral neck in a child aged seven. Figure 9-Three months later. Appearances of avascular necrosis of femoral neck. Note that the epiphysis is quite unaffected. Figure 10-Two years later. Premature fusion across upper femoral epiphysial plate.

plate acts as a barrier. Second, the blood supply to the epiphysis is derived almost entirely from the lateral epiphysial vessels and the contribution from the vessels along the ligamentum teres is small and confined to a segment of the epiphysis.

When a fracture occurs the blood supply from the nutrient vessels is divided (Fig. 11). If the important lateral epiphysial vessels are all damaged (at site $A$ ) then the entire proximal fragment will become avascular, since the contribution from the ligamentum teres and inferior metaphysial vessels is slight. This will lead to a severe diffuse necrosis (Type I). If the blood supply from the lateral epiphysial vessels remains intact and only the superior metaphysial vessels are damaged (at site B), then the femoral neck alone will become avascular (Type III). 
Finally, if the lateral epiphysial vessels are damaged (at site C) immediately before they enter the epiphysis then a localised form of necrosis will occur (Type II).

I am fully aware that this explanation is hypothetical. Nevertheless it is thought

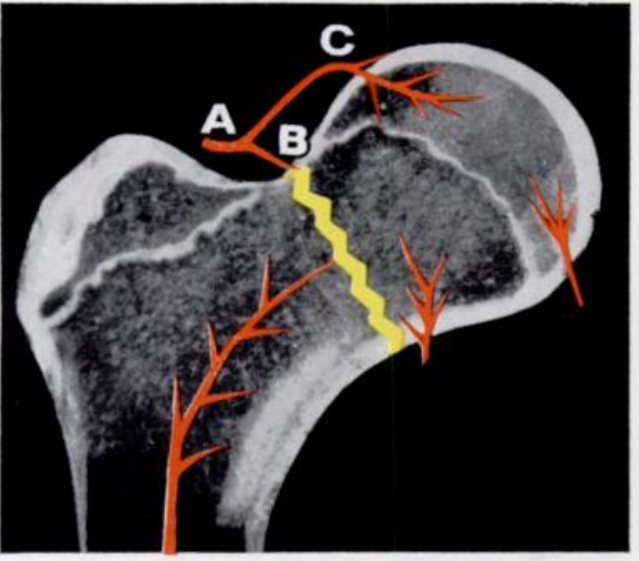

FIG. 11

Diagrammatic illustration of the blood supply of the head and neck of the child's femur (from Trueta 1957). worthy of inclusion as it is supported by the experimental work of Trueta (1957). Further, it should be noted that with one exception, every patient who developed avascular necrosis of the femoral neck was aged eleven years or less at the time of the injury; presumably in older patients an anastomosis developed across the closing epiphysial plate and therefore localised changes in the femoral neck were unlikely to occur.

\section{THE RELATION OF AVASCULAR NECROSIS TO "PERTHES' DISEASE "}

The radiographic appearances of avascular necrosis after a fracture of the femoral neck are different from the radiographic appearances seen in patients suffering from pseudocoxalgia (Legg-Calvé-Perthes' disease). I did not observe in the upper femoral nucleus of any patient the cycle of changes of increased density, flattening, fragmentation and later reformation, so characteristic of this condition.

Naerra (1937), Nielsen (1938), Watson-Jones (1955) and McDougall (1961) state that the conditions of avascular necrosis after a fracture of the femoral neck in a child and of Perthes' disease are similar, but I have found only one case in the literature where serial radiographs confirm this statement (Nielsen 1938). It should, however, be recorded that in one patient a radiograph showed a uniformly increased density of the upper femoral nucleus (Fig. 12) but no fragmentation of this nucleus, or broadening of the metaphysis, was present in subsequent radiographs. These changes were exceptional and did not conform to any of the three patterns of necrosis mentioned previously.

Finally no evidence was found that avascular necrosis after a fracture of the femoral neck was localised to the anterior segment of the epiphysis as has recently been described by O'Garra (1959) in Perthes' disease. If we can assume that these changes after a fracture of the femoral neck are due to arterial damage (and the nature of the violence and localisation of changes to the proximal fragment seem to make this a fair assumption), then it seems that these facts offer new and indirect evidence that

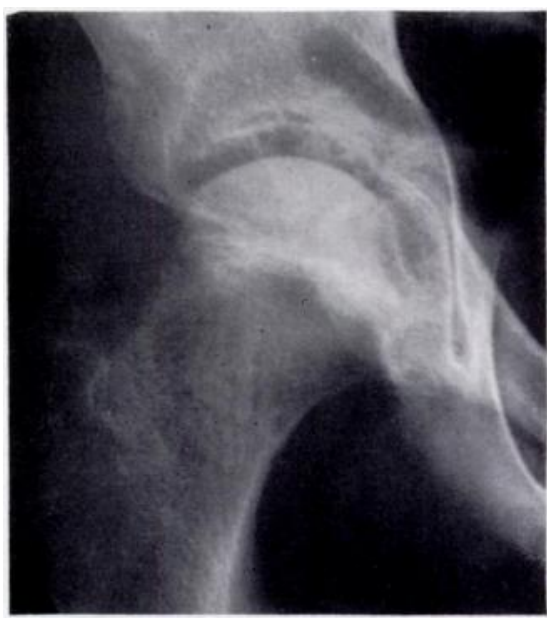

FIG. 12

Changes resembling those of Perthes' disease in the femoral head of a boy of thirteen who four months previously sustained a transcervical fracture without displacement. The fracture line is just visible. Perthes' disease is not a simple avascular necrosis due to damage to arterial blood supply. For these reasons I cannot agree with Durbin (1959) that the appearances of avascular necrosis after a fracture of the femoral neck in a child " give support to the traumatic theory of origin of Perthes' disease." 


\section{DELAYED UNION AND NON-UNION}

Delayed union is an arbitrary term which cannot be precisely defined. I have applied it to cases where radiographic evidence of union was not seen five months after injury. Delayed union occurred in seventeen patients and in a further seven non-union developed. A coxa vara deformity associated with slow union occurred in fourteen patients. It may be concluded that defects of union are frequent after a displaced fracture of the femoral neck in a child (Fig. 13).

Non-union occurred in several circumstances. Union failed in four patients where a displaced fracture was treated by manipulative reduction and immobilisation of the hip in a plaster spica; in one an adequate reduction was not achieved (Fig. 14), and in three displacement of the fragments recurred. Non-union occurred in two patients where internal fixation of the fragments had been attempted but had proved impossible for technical reasons. Finally, union failed in one patient with multiple injuries, including gross skin loss over the injured hip, where satisfactory initial treatment of the fracture could not be carried out. Non-union did not occur after adequate primary internal fixation or after primary subtrochanteric osteotomy.

The treatment of non-union was never easy. Two patients obtained good results after a

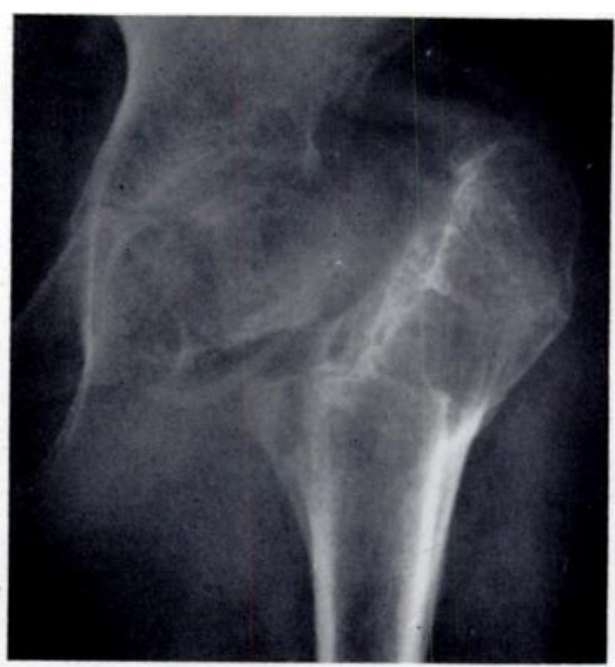

Fig. 13

Radiograph of the hip of a boy aged twelve showing established non-union one year after a displaced fracture of the femoral neck. The fracture was primarily treated by manipulative reduction and plaster immobilisation. Later, open reduction and finally osteotomy were performed but without success. bone-grafting operation. In one the bone graft was accompanied by internal fixation and in the other the graft was accompanied by a displacement osteotomy. The radiographs of one of these patients are shown in Figures 14 to 17 .

\section{PREMATURE EPIPHYSIAL FUSION}

Premature fusion at the upper femoral epiphysial plate occurred in eleven patients. In six of these premature fusion followed avascular necrosis of the femoral neck; this has already been discussed. In three patients premature fusion occurred at the lower femoral epiphysial plate, resulting in shortening of the leg of five, three and a half and one and a half inches respectively. In these patients salvage operations were performed in an endeavour to achieve union of the fracture and such operations necessitated prolonged immobilisation. An example of a poor result with premature fusion at the knee is shown in Figures 18 to 20.

\section{TREATMENT}

Undisplaced fracture-Several methods of treatment were employed in the management of twenty-one undisplaced fractures. The technique most frequently used was immobilisation in a plaster spica (fifteen patients), but a Thomas's splint (two patients), bed rest without splintage (one patient), fixation on a frame (two patients) and internal fixation (one patient) were also employed.

In sixteen patients who obtained a good result the fracture united rapidly without complications. Of the three who obtained a fair result, two developed mild avascular necrosis without collapse of the upper femoral epiphysis. In the third patient displacement of the 


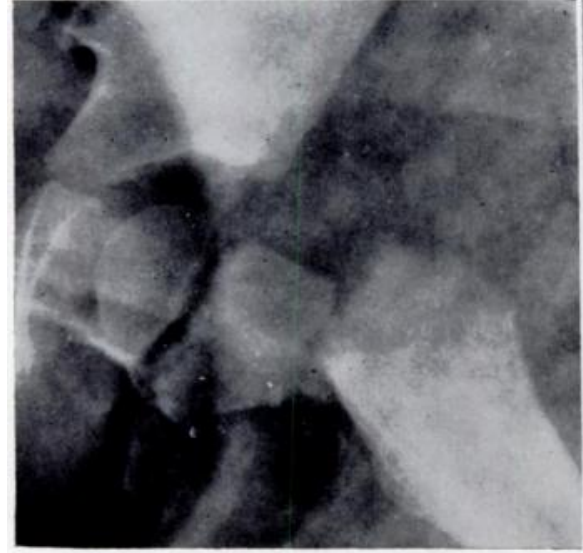

FiG. 14

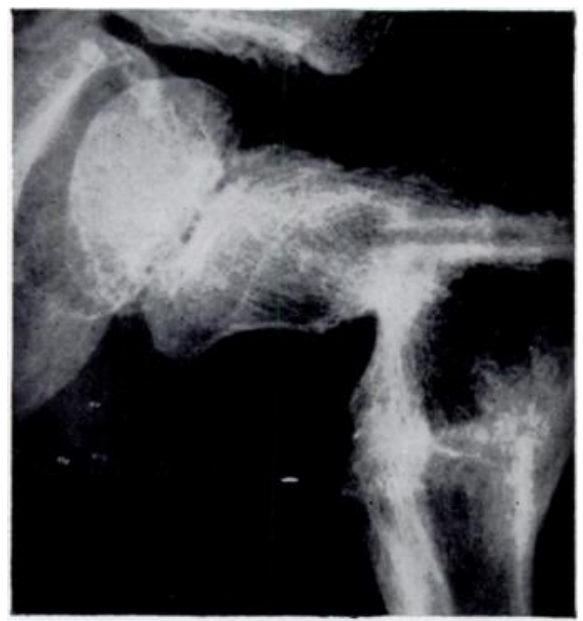

FiG. 16

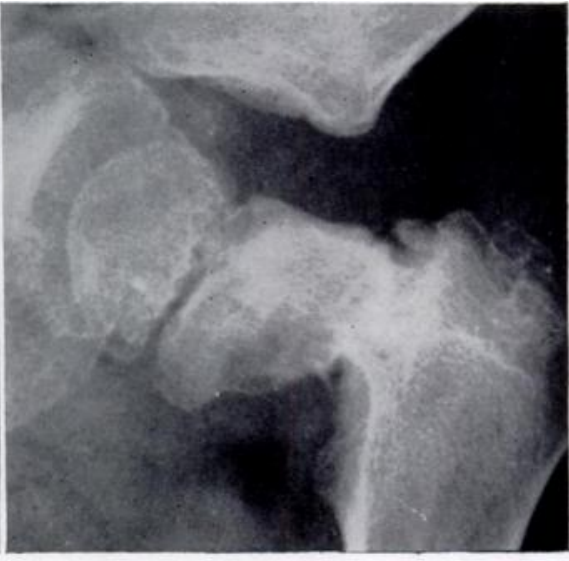

FIG. 15

Figs. 14 To 17

Non-union of fracture of the femoral neck; results of treatment. Figure 14Fracture of the femoral neck in a child of four. Appearances shortly after primary treatment and plaster immobilisation. Adequate reduction not achieved. Figure 15-Appearances eighteen months later: non-union and coxa vara. Figure 16Appearances four months after combined bone graft and osteotomy. Note the persisting coxa vara. Figure 17Seven years later. With growth and remodelling the coxa vara has become less, and an almost normal hip and a good result have been achieved.

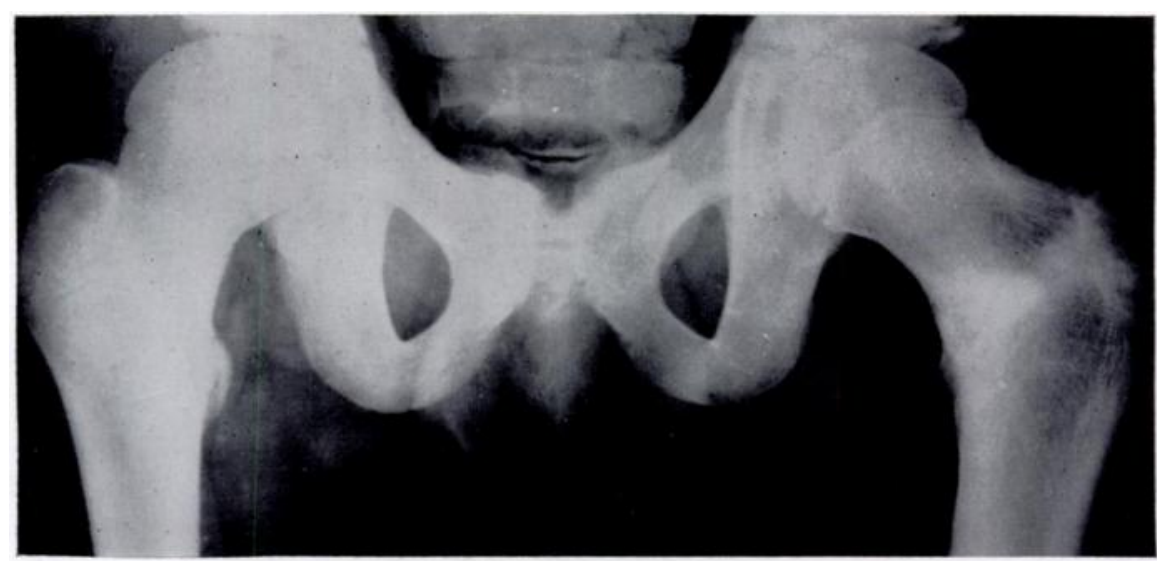

Fig. 17 
fragments of the fracture occurred within three weeks after injury, whilst the hip was immobilised in a plaster spica; delayed union developed, requiring a bone-grafting operation. In the two patients who obtained poor results severe avascular necrosis developed; their

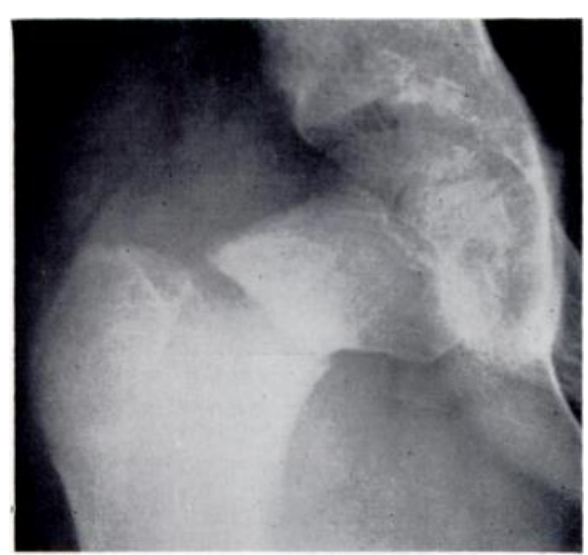

Fig. 18

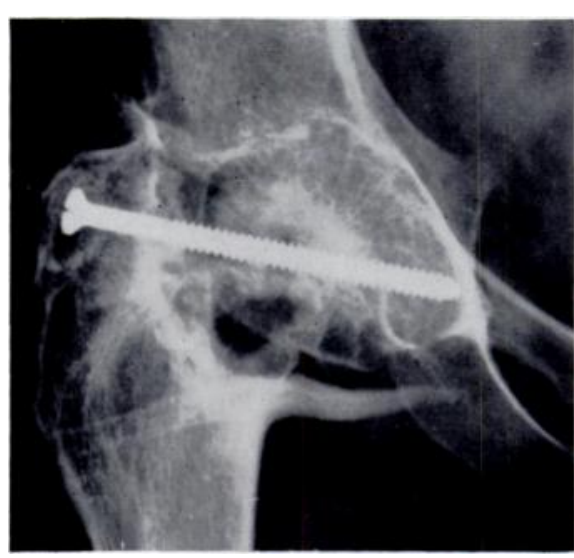

FIG. 19

Non-union of fracture of femoral neck; failure of treatment ; premature fusion across epiphysial plates of knee. Figure 18-Fracture of right femoral neck in a girl aged eleven. Figure 19-Three years later, after primary treatment by manipulative reduction and internal fixation with trifin nail, later open reduction and fixation, and finally attempted arthrodesis.

radiographs have already been published (Durbin 1959). It appears from this series of twenty-one cases that the management of an undisplaced fracture of the femoral neck in a child should be considered easy: good results are to be expected from any sound method of conservative care. The method of treatment preferred by the author is immobilisation in a single plaster spica. Exceptionally, avascular necrosis may develop, leading to a fair or poor result. Prediction of avascular necrosis is impossible.

Displaced fracture-In sharp contrast the treatment of a displaced fracture was less satisfactory. A good result from primary treatment was obtained in only fifteen patients-less than one-third. In a further seven patients a good result was eventually achieved after a salvage procedure. Seven methods of primary treatment were employed and are shown in Table IV.

Manipulative reduction and immobilisation in a plaster spica-This method was employed in nineteen patients. The results of treatment by this method are summarised in Table V.

This method of treatment is not recommended. In fifteen out of nineteen patients the fracture was

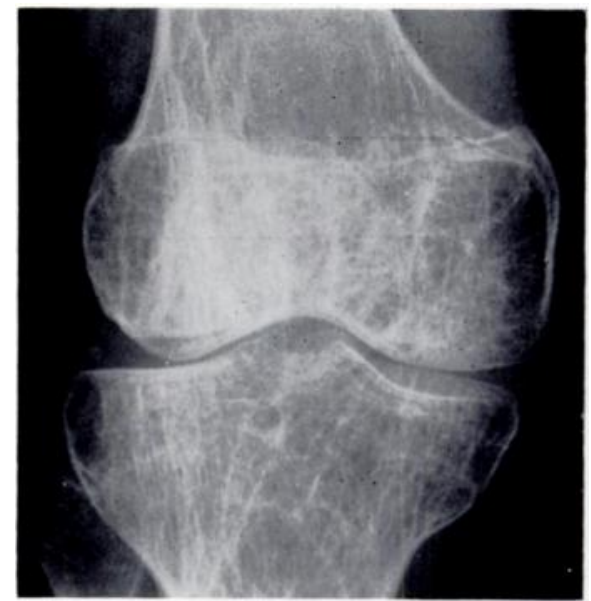

FIG. 20

Same case as Figures 18 and 19. Radiograph of the right knee three years after injury. Premature epiphysial fusion had caused three and a half inches of shortening. not reduced or the fragments became displaced after reduction. Only two children obtained a good result though a further six good results were achieved after salvage procedures.

Manipulative reduction and internal fixation-This method was employed in nineteen patients. This operation is difficult to perform in young children and it was noteworthy that it was only attempted in one patient under the age of eleven years at the time of injury. It was attempted in fifteen patients with transcervical fractures and four with basal. Various types of internal 
fixation were used, including a Smith-Petersen pin (eleven children), a Charnley screw (two children), an Austin Moore pin (two children), a blade-plate (three children) and a WatsonJones nail (one child). The results of treatment were: good-nine; fair-five; poor-five.

Thus it will be seen that less than one-half of these patients obtained a good result. It is of interest that in two patients with displaced fractures of the femoral neck a lag screw designed by Charnley (1960) was inserted; good results were obtained.

Manipulative reduction and Thomas's splint-This method was used in three patients. The result was good in one patient and poor in two, both of whom required salvage operations

TABLE IV

The Primary Treatment of Displaced Fractures in Forty-nine Patients

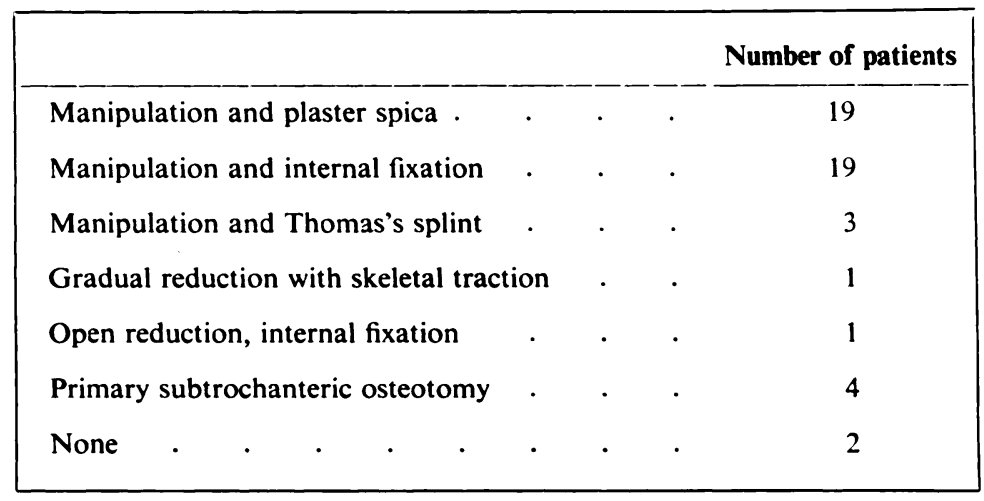

TABLE V

The Results of Treatment by Manipulative Reduction and Plaster Spica in Nineteen Patients

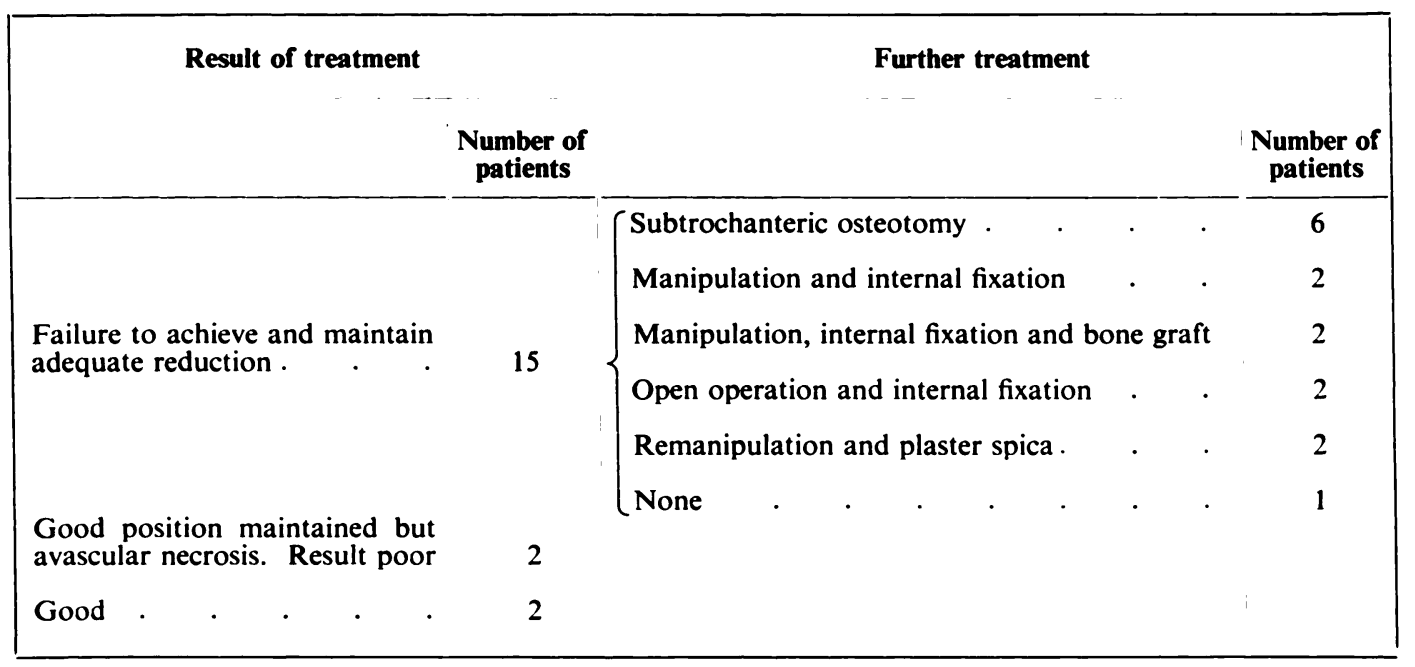

for delay in union. The Thomas's splint was not designed to maintain the reduction of a fracture of the femoral neck and this method is not recommended.

Primary subtrochanteric osteotomy-This was performed in four patients, in three because of failure of manipulative reduction; in two cases the result was good and in the other two fair. No poor results occurred and no secondary operations were necessary. An example of a good result of treatment by this method is shown in Figures 21 to 23. The remarkable remodelling of the upper end of the femur with growth is noteworthy. 


\section{SECONDARY TREATMENT OF DISPLACED FRACTURES}

Secondary procedures were required in nineteen patients with displaced fractures of the femoral neck (Table VI). In four of these cases more than one salvage procedure was carried out. Arthrodesis of the hip was eventually performed in three patients.

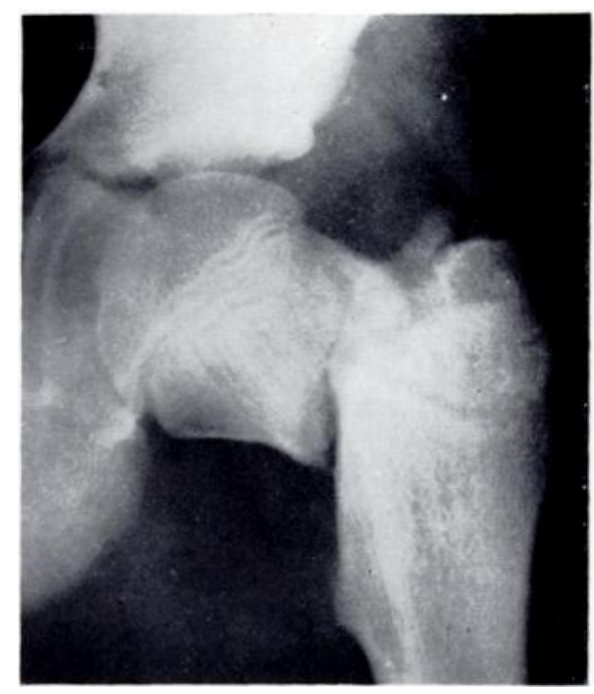

FIG. 21

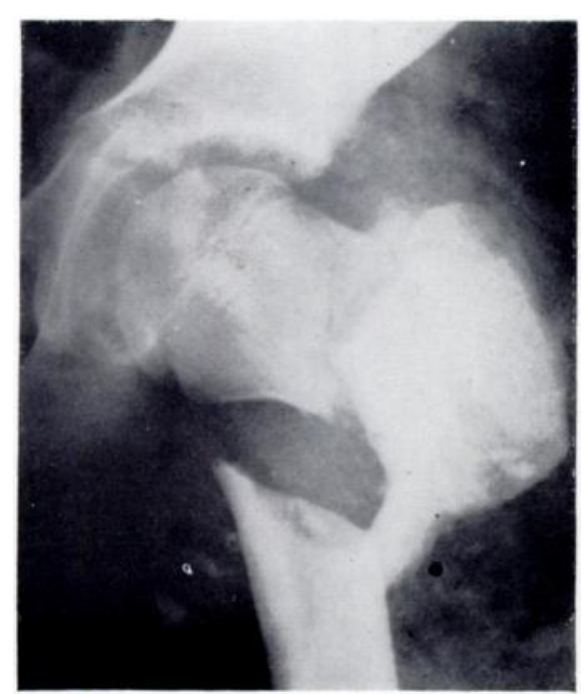

FIG. 22

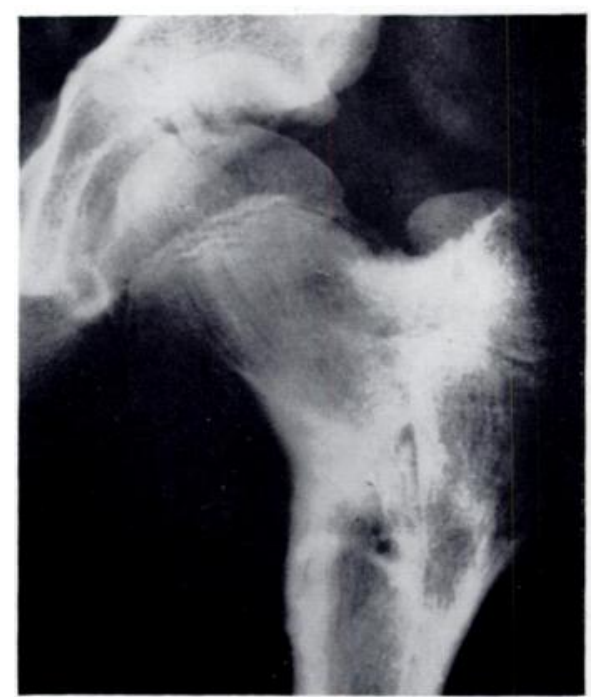

Fig. 23

Successful treatment by primary osteotomy. Figure 21-Displaced transcervical fracture of neck of left femur in a boy aged eleven, who had fallen twenty feet. Figure 22-The position after osteotomy performed because of failure to achieve reduction by manipulation. The site of osteotomy was low and the femur split. Figure 23-Radiograph taken five years after injury, showing how remodelling of the upper end of the femur has produced an almost normal bone and joint.

The most frequent indication for secondary treatment was recurrence of displacement of the fragments, despite a plaster spica or a Thomas's splint, often with delayed or non-union. These operations will not be discussed in detail. They were difficult technical procedures and these children were often immobilised for many months; the result of treatment could be as disastrous as that illustrated in Figures 19 and 20. It is, however, of some interest to note the results of late subtrochanteric osteotomy. 
In ten otherwise hopeless cases this operation produced eight reasonable results (goodtwo; fair-six), and it seems that osteotomy is a valuable procedure in the management of some of these difficult problems.

The value of internal fixation of the fragments after osteotomy cannot be discussed in detail for in this series there were only two patients so treated. It is the author's impression that the best results of osteotomy were obtained when the displacement was slight and internal fixation not employed.

TABLE VI

Secondary Procedures Performed for fallure of Treatment in Nineteen Cases of Fracture of the femoral Neck in Childhood

\begin{tabular}{|c|c|c|}
\hline & & Number of children \\
\hline Subtrochanteric osteotomy . & . & 10 \\
\hline Manipulation and plaster spica . & . & 2 \\
\hline Manipulation and internal fixation & . & 2 \\
\hline Manipulation, internal fixation and bor & ne graft & 2 \\
\hline Open operation and internal fixation & . & 2 \\
\hline Arthrodesis & . & 1 \\
\hline
\end{tabular}

TABLE VII

Methods of Primary Treatment of Fifteen Cases of Displaced Fracture of the Femoral Neck in a Child Leading to a Good Result

\begin{tabular}{|c|c|c|}
\hline & & Number of patients \\
\hline \multicolumn{3}{|c|}{ Manipulative reduction and internal fixation: } \\
\hline Smith-Petersen pin & . & 3 (out of 11 ) \\
\hline Charnley screw & . & 2 (out of 2 ) \\
\hline Blade plate. & . & 3 (out of 3 ) \\
\hline Moore pins & . & 1 (out of 2 ) \\
\hline \multicolumn{2}{|c|}{ Manipulative reduction and plaster spica } & 2 (out of 19 ) \\
\hline \multicolumn{2}{|c|}{ Manipulative reduction and Thomas's splint } & 1 (out of 3 ) \\
\hline \multicolumn{2}{|c|}{ Primary subtrochanteric osteotomy } & 2 (out of 4 ) \\
\hline \multicolumn{2}{|c|}{ Gradual reduction and later plaster spica } & 1 (out of 1 ) \\
\hline
\end{tabular}

\section{DISCUSSION}

Treatment of displaced fractures-It will be clear from this study that good results can be achieved in the management of a displaced fracture of the femoral neck in a child by several methods of treatment (Table VII).

What is the best? A categorical statement cannot be made.

Manipulative reduction and internal fixation, providing a good reduction can be obtained, offers approximately a 50 per cent chance of a good result. With rare exceptions it is unlikely that this operation can be performed in children younger than about ten years of age; it is a difficult procedure. This series is not large enough for analysis of the value of different types of internal fixation. However, distraction of the fragments by a three-flanged nail was 
mentioned by McDougall (1961) and two further cases were noted in this series. For this reason it is probably not wise to use a Watson-Jones nail or a Smith-Petersen pin.

Manipulative reduction and immobilisation in a plaster spica is not recommended. The fragments have redisplaced (if indeed adequate reduction was achieved) in a high proportion of cases. It must be admitted that good results have eventually been achieved in some of these cases by secondary salvage procedures.

Primary subtrochanteric osteotomy was employed in only four patients. The conclusions expressed are therefore tentative and are based more on general principles than on statistical evidence. No bad results occurred and no secondary operations were necessary. It has been seen that with growth remodelling of the femoral neck does occur after this operation and may restore normal anatomy. Some shortening may, however, result; none of these four children was observed for more than eleven years, and the ultimate results in adult life are not known.

TABLE VIII

Suggested Plan of Treatment of Fractures of the Femoral Neck in Children

\begin{tabular}{|c|c|c|c|}
\hline \multirow{4}{*}{$\begin{array}{c}\text { Undisplaced fracture } \\
\text { Plaster spica }\end{array}$} & \multicolumn{3}{|c|}{ Displaced fracture } \\
\hline & \multirow{3}{*}{$\begin{array}{l}\text { Under ten years } \\
\text { Primary osteotomy }\end{array}$} & \multicolumn{2}{|c|}{ Over ten years } \\
\hline & & \multicolumn{2}{|c|}{ Manipulative reduction } \\
\hline & & $\begin{array}{l}\text { Successful } \\
\text { Internal } \\
\text { fixation }\end{array}$ & $\begin{array}{c}\text { Unsuccessful } \\
\text { Primary } \\
\text { osteotomy }\end{array}$ \\
\hline
\end{tabular}

I consider that primary osteotomy may be indicated in two circumstances, either in a displaced fracture of the femoral neck in a child under ten years of age, or in such a fracture in an older child where a good manipulative reduction cannot be achieved.

Finally, it is clear that a displacement osteotomy may play a part as a secondary salvage operation in the presence of complications such as delayed and non-union.

The plan of treatment outlined in Table VIII may perhaps be suggested as a general scheme for the management of these difficult cases.

\section{SUMMARY AND CONCLUSIONS}

A study of a collected series of femoral neck fractures in seventy-one children observed for one to nineteen years shows:

1. This injury is rare but occurs in children of all ages from three to sixteen years old.

2. The fractures may be classified as transepiphysial, transcervical (the commonest), basal and pertrochanteric. Displacement was frequent.

3. The fracture usually followed severe violence, especially falls from a height or motor accidents.

4. Complications were frequent and included avascular necrosis, delayed union (seventeen cases), non-union (seven cases) and disturbances of growth at both the upper and lower ends of the femur.

5. Avascular necrosis occurred in thirty patients ( 42 per cent). Three patterns of necrosis are described: diffuse, localised and confined to the femoral neck. The radiographic appearances of avascular necrosis after this fracture are different from those of pseudocoxalgia (LeggCalvé-Perthes' disease).

6. Non-union did not occur after adequate primary internal fixation or after primary subtrochanteric osteotomy.

vol. 44 B, NO. 3, AUguSt 1962 
7. The management of an undisplaced fracture presented no great problem and the results were good. A plaster spica is recommended for treatment of this fracture. Exceptionally, avascular necrosis developed.

8. Treatment of the displaced fractures (forty-nine cases) was less satisfactory. A good result was obtained from primary treatment in only fifteen patients.

9. The value of different methods of primary treatment is discussed, including manipulative reduction and immobilisation in a plaster spica, manipulative reduction and internal fixation, and primary subtrochanteric osteotomy. Manipulative reduction and immobilisation in a plaster spica is not recommended.

10. Salvage operations were required in nineteen patients. Late subtrochanteric osteotomy is of value in the management of some of these problems.

The following surgeons and their assistants have allowed me to study the documents and radiographs of their cases. Without their help this paper could not have been prepared.

Mr R. W. Agnew, Mr G. W. Baker, Mr J. Bastow, Mr N. J. Blockey, Mr B. H. Burns, Mr H. Jackson Burrows, Mr N. L. Capener, Mr J. Charnley, Mr E. A. Chisholm, Mr C. H. Cullen, Mr F. C. Durbin, Mr F. C. Dwyer, Mr J. S. Ellis, Mr T. J. Fairbank, Mr C. W. Flemming, Mr A. T. Fripp, Mr A. Glass, Mr D. Ll. Griffiths, Mr J. C. R. Hindenach, the late Mr C. G. Irwin, Mr C. C. Jeffery, Mr E. W. Knowles, Mr G. J. Lillie, Mr P. S. London, Col. H. S. McBurney, Mr G. K. McKee, Mr R. H. Metcalfe, the late Mr A Miller, Mr S. M. Milner, Mr A. Naylor, Mr K. I. Nissen, Mr H. Osmond-Clarke, Sir Harry Platt, Mr R. Roaf, Mr C. G. Rob, Mr D. L. Savill, Mr W. Sayle-Creer, Mr J. H. Shelswell, Mr N. R. Smith, Mr S. M. Thompson, Mr O. J. Vaughan-Jackson, Mr F. T. Wheeldon and Mr M. E. Winston.

Particular thanks are due to $\mathrm{Mr} \mathrm{D}$. Ll. Griffiths for his constant help and encouragement and for reading and criticising the manuscript. I am also grateful to the Departments of Medical Illustration of Manchester Royal Infirmary and Southend General Hospital.

\section{REFERENCES}

Blount, W. P. (1955): Fractures in Children. Baltimore: The Williams \& Wilkins Company. London: Baillière, Tindall \& Cox.

Carrell, B., and Carrell, W. B. (1941): Fractures in the Neck of the Femur in Children with Particular Reference to Aseptic Necrosis. Journal of Bone and Joint Surgery, 23, 225.

Charnley, J. (1960): Personal communication.

Colonna, P. C. (1928): Fracture of the Neck of the Femur in Childhood. A Report of Six Cases. Annals of Surgery, 88, 902.

Durbin, F. C. (1959): Avascular Necrosis Complicating Undisplaced Fractures of the Neck of Femur in Children. Journal of Bone and Joint Surgery, 41-B, 758.

Green, W. T. (1953): Discussion on Fractures of the Hip in Children. Journal of Bone and Joint Surgery, 35-A, 886.

Ingram, A. J., and BAChynski, B. (1953): Fractures of the Hip in Children. Journal of Bone and Joint Surgery, 35-A, 867.

McDougall, A. (1961): Fractures of the Neck of the Femur in Childhood. Journal of Bone and Joint Surgery, 43-B, 16.

Naerra, A. (1937): On Secondary Epiphyseal Necrosis After Collum Femoris Fracture in Young Persons. Acta Chirurgica Scandinavica, 80, 238.

Nielsen, B. (1938): Om Calvé-Perthes Sygdom efter Fractura colli femoris hos unge of dens Betydning for Forstaaelsen af de aseptiske Epifysenekrosers Patogenese. Hospitalstidende, 81, 773.

O’Garra, J. A. (1959): The Radiographic Changes in Perthes' Disease. Journal of Bone and Joint Surgery, 41-B, 465.

Trueta, J. (1957): The Normal Vascular Anatomy of the Human Femoral Head During Growth. Journal of Bone and Joint Surgery, 39-B, 358.

Watson-Jones, R. (1955): Fractures and Joint Injuries, p. 72. Edinburgh: E. \& S. Livingstone.

Whitman, R. (1900): Further Observations on Depression of the Neck of the Femur in Early Life; Including Fracture of the Neck of the Femur, Separation of the Epiphysis and Simple Coxa Vara. Annals of Surgery, 31, 145. 